\title{
A rounded picture is what we need: Rhetorical strategies, arguments, and the negotiation of change in a UK hospital trust.
}

\author{
Frank Mueller, John Sillince, Charles Harvey and Chris Howorth
}

\begin{abstract}
This article is concerned with the introduction of the agenda of New Public Management (NPM) within the board of a UK Hospital Trust: West London Hospital (WLH). We discuss the literature on New Public Management, including its limitations for analysing the organizational reality of implementing NPM. But we will also be drawing on discourse theory and the literature on rhetoric. The main argument in this article is that in order to understand the reality of the NPM paradigm, we need to study the rhetorical strategies of protagonists involved in the negotiation of the NPM agenda. Rhetorical strategies are means of making general viewpoints more convincing, for example, by comparing 'our' organization with similar organi-zations. Rhetorical strategies show patterns, which reappear in conversations and arguments made by protagonists. Specifically, we identified three rhetorical strategies justifying why and what kind of a more 'rounded picture' was required: widening the argument to include national productivity comparisons with other hospitals; widening the argument away from a narrow focus on finance toward a strategic and political perspective; and, lastly, widening the argument to look at innovation in the whole clinical process.
\end{abstract}


In 1995, Hood posed the question of whether NPM had emerged as a new global paradigm in contemporary public management. Indeed, since then a large number of publications have appeared that deal with the introduction or implementation of some aspects of NPM in countries across the world: Norway (Christensen and Laegreid 1999), Denmark (Borum 1999; Jespersen 2000), The Netherlands (Groot 1999) and the UK (for example, Ferlie et al. 1996; Kitchener $1998,1999)$ among many others. Many of the quoted studies acknowledged that there is not a simple adoption of a globally uniform standard, but, instead, that there is 'a complex interplay' between the global and the local (Christensen and Laegreid 1999: 186). This would suggest that there is a need for in-depth research looking at variations of this 'complex interplay'. In this article, we will be analysing the behavioural and rhetorical mechanisms involved in negotiating the 'realization' of NPM principles in the context of an NHS Hospital Trust.

In the context of substantive changes sweeping over the Trust, NPM-like arguments were employed in board meetings by some board members and it is the contentious discussion of these arguments that is the subject for the rest of this article. The remainder of this article is divided into four parts: section two deals with the relevant literature. Section three outlines the methodology employed for studying the case; section four deals with various aspects of the rhetorical contestation of NPM; section .ve provides a discussion of the .ndings; lastly, section six provides a summary and the implications for theory and literature.

\section{Literature}

\section{Rhetoric and Discourse}

Organizations are environments in which ambiguity in discourses is common-place and where the resulting incoherence is normal. Indeed, it is unsurprising that nance is drawn into political debate and that this process involves rhetorical construction of issues and uses (seemingly) rational argumentation (Shapiro 1998). Indeed, institutions use legitimizing rhetoric, which differs from the actual content of their policies (Bealing et al. 1996). The 'bottom line' is a cliché used in order to elevate hierarchically accounting and nance considerations (Anderson-Gough et al. 1998). Arnold and Oakes (1998) showed how the US retiree health bene.ts crisis was discursively constituted by two competing rhetorics: one portraying the situation in terms of moral obligations that firms were attempting to avoid and the other portraying the same situation as unexpected liabilities threatening corporations. In a health 
context, we would expect different perspectives on what should take priority, for example, money as something to be careful spending too much of, as against money as an opportunity to raise the quality and effectiveness of care. This discussion suggests that we need to take into account the use of rhetorical devices in order to understand the way members of organizations deal with discursive ambiguity and inconsistency.

\section{New Public Management and the NHS}

Public-sector managers will define performance according to a number of dimensions, with regard to a range of constituencies (Ackroyd et al. 1989). NPM as a project has aimed at reducing this ambiguity: indeed, two of the elements of NPM are a stress on private-sector styles of management practice and more stress placed on financial discipline and frugality in resource use (Hood 1995). The latter also means that there is a constant search for alternative, less costly ways of delivering public services, instead of placing emphasis on institutional continuity, maintenance of public services in volume terms, and policy development (Hood 1995). Typical justifications are the need to apply proven private-sector management tools in the public sector and a need to adopt strict financial discipline, cut direct costs, raise labour discipline, and do more with less. Although Hood (1995) identified seven attributes of NPM, we will concentrate on two core points, as they have the greatest thematic relevance for our narrative: getting better value for money from resources (use), including HR resources, in order to implement a much tighter regime of financial discipline and balanced books, and the systematic application of private-sector management practices, tools, and techniques. It has been common to distinguish three factions in professional, especially health service, organizations: non-executive directors (including the chairman), executive managers (including the chief executive officer and finance director), and clinical executive directors (medical and nursing directors). While descriptions of these three factions will show basic similarities across countries (for an analysis regarding Canada, see Denis et al. 2001), there are also some significant differences between countries. In the UK, non-executive directors (often senior business executives), ultimately, are legitimized in their role by government (Ashburner et al. 1996: 4-5), notionally representing communities of interest such as patients and taxpayers. The tendency is for non-executives, unfamiliar with professional and organizational details, to question decisions and to pursue 'best value' on the basis of general managerial principles derived from private-sector norms and models. In contrast, executive board members with a clinical background are 'insiders' in command of professional and organizational details, partially legitimized in their role by membership of the medical establishment. Their mind-set is professional and the pursuit of clinical quality a goal to be defended against the potentially damaging consequences of 'managerialism'. Evidence suggests that their identity is still mainly formed through their membership of the medical domain, and managerial responsi-bilities accepted where they are seen as non-challenging (Harrison and Pollitt 
1994). In short, clinical directors were found to 'protect high levels of clinical autonomy and resist attempts to enhance the managerial control of medical practice' (Kitchener 2000: 150). The literature has often described the defensive strategies employed by clinical staff in fending off what was seen as managerial intrusion. However, this assumes that the professional value system does not evolve, is and remains completely antithetical to the managerialist value system. We, however, contest this assumption on the following grounds. First, each faction in itself is not completely homogenous, either in structural or in ideological terms (Whittington et al. 1994). Second, the pervasiveness of the NPM discourse has meant that, at least in a policy context, it can no longer simply be dismissed out of hand or ignored. We are not, however, challenging Kitchener's (2000: 150) point that clinical directors were found to 'protect high levels of clinical autonomy and resist attempts to enhance the managerial control of medical practice'. All we are saying is that NPM needs to be rhetorically engaged with, and this might involve accepting certain points or aspects of it. It is rhetorically unpersuasive to dismiss it as nonsense or simply to ignore it.

We will be looking in more detail at different rhetorical strategies, specifically, the way different factions make (different) sense of the notion of looking at a 'rounded picture'. Under conditions of a challenge from NPM, ambiguity is heightened within a hospital setting, because in addition to quality of medical care considerations and aspects of clinical innovation, there are also costsaving pressures. The focus of our article is therefore an analysis of an ambiguous context that is amenable to be interpreted and talked about in different ways. Thus, this article attempts to go beyond simply describing a situation of conflict — rather, we want to analyse how language is used in order to engage with others, while at the same time pursuing one's own agenda.

\section{Data Collection, Methodology, and Background to the WLH Case}

We propose to study the utilization of rhetorical strategies in order to make arguments more convincing. In the present article, we will be analysing this connection mainly through participant observation of board-level interaction, complemented by documentary evidence (including a large number of board minutes, of.cial communications, and letters) and two rounds of semistructured interviews with all board members. We draw upon longitudinal research (1996-99) into the governance of WLH, a politically high-pro.le NHS Trust. Two of the present authors were also involved during this period in research using a different data set (a separate participant-observation study which used access to a different set of meetings, documents, and interviews) on a new ambulatory care centre at WLH, with its concomitant culture-change programme, so the data considered here is part of a much larger data set.

In drawing up a suitable methodology for our study, we heeded the advice of Greenwood and Hinings (1993: 1074) of the importance of paying careful 'attention to the biography of the organisation under scrutiny'. This research 
follows a qualitative, grounded theory methodology (Strauss and Corbin 1990). This method is especially suited to the current research, being widely used in research on organizational change in professional settings, especially health care and education (Denis et al. 2001). The project was initiated through a series of (10) interviews with the WLH board team (including both executive and non-executive directors). These interviews were followed up by both participant observation (one of the researchers was a member of the board team) and non-participant observation (another of the researchers was a frequent observer of board meetings and discussions between various board members). This enabled us to make the assumption that the views expressed in interviews are reasonably representative of positions taken in board meetings. During this period a number of informal discussions were held with board members, and a full set of public and non-public board papers was collected. At the end of the study period a further series of (12) interviews was held with the board team. These interviews were carried out with the (eight) members of the board team who remained in place throughout the research period, together with (four) new members of the board who were not interviewed in the initial interviews.

Interviews were seen as an appropriate research method, given that they would provide high validity in terms of advanced understanding of the linguistic and social categories used by protagonists in order to make sense of their situation (Coffey and Atkinson 1996). Both rounds of interviews were designed in order to understand the role of each member of the board team, and to elucidate the differing views held by them with regard to changes and challenges and also the functioning of the board team. Questions asked included 'What have been the key drivers of change during the most recent period?' 'What changes have been made that were most important to you?' 'What are the key problems that the Trust has experienced?' 'What are the key managerial problems that you personally face at the Trust?' and 'What are the main successes and failures?' In order to provide a framework for this research and to provide focus for the various areas of negotiation and agenda setting revealed, emphasis was placed on the .nancial crisis, which swept over the hospital Trust at a time when it was engaged on a major reengineering exercise.

Board-level data are scarce (Pettigrew 1992; McNulty and Pettigrew 1999: 49; Richter 1998: 306), and have their limitations. Especially for our purposes, they will not always provide a full picture of the organization-wide values, beliefs, and discourses. They will give some indication about the processes of politics, ideology, and influence, but will not give us the 'full picture'. The extensive primary material gathered through interviews, observation, and documents has been analysed with reference to the body of theory outlined above. The primary purpose of this research was therefore not generalization, but increased understanding of a particular situation, which will be seen as, in some respects, typical for similar situations (Eisenhardt 1989; Pentland 1999; Langley 1999). Our longitudinal case study is, we believe, highly valid in providing an indepth account of the rationales, interpretations, and language use of agents in the specific, chosen organization. The account is 'true' and 
truthful in the sense that the subjects involved (as authors of text or speech) have made every effort to eradicate interference of bias. In this sense, it is reasonable and probable (Miles and Huberman 1994). But our account is not necessarily representative of what is happening in other, similar organizations. Our account helps us in understanding how subjects make sense of the world, but it does not necessarily help us in building causal input-output models (Silverman 1993). In terms of limitations, our access was through, and therefore limited to, the board. This meant that the professional interpretive scheme, which would need to be studied also through speech acts and the actions of consultants, was only accessible via the medical director and nursing director. Both of these were, however, influenced to varying degrees by also being members of the executive.

Particular attention is given in what follows to the negotiation of two elements of NPM, both of which were a persistent source of discussion and debate. These were financial constraints and clinical innovation.

\section{The Rhetorical Construction of a 'Rounded Picture' Background}

By way of background, WLH was one of the first six hospitals in the UK to be granted trust status, and throughout the 1990s, the hospital was identified with the pursuit of a radical clinical agenda. This had four main elements. The first was to develop and implement a new model of clinical care. Emergency and elective services were separated (to prevent the cancellation of planned operations during periodic emergency admission crises) and services reorganized through the application of clinical protocols (to improve outcomes and patient flow, and to reduce bed numbers and patient length of stay in hospital). The second was to participate as a beacon site in a series of government-funded modernization projects such as 'patient-focused care' and 'direct booking' (of elective patients into hospital by general practitioners). Such participation was used to generate additional strategic resources and to build a reputation for innovation. The third element was to upgrade the hospital's staffing base in support of the clinical strategy. More consultants were hired in order to offer a wider range of consultant-led (as opposed to predominantly junior doctor staffed) services and to enable consultants to spend more time training juniors. At the same time, the senior nursing role was expanded through training and the introduction of clinical protocols, such that 'nurse practitioners' could undertake many of the tasks once performed by doctors (by 1999 more than 60 percent of accident and emergency attendees never saw a doctor). These promising developments on the innovation side were simultaneous with ongoing financial problems. Thus, the discursive background to our study is provided by the interrelated issues of consultant numbers, productivity, financial control, clinical innovation, and a stated over-reliance on 'politics' to cover holes in the budget. Our central argument is that, while different arguments were discernible in the 
board, they all seemed to embrace the rhetorical point that a 'rounded picture' needed to be considered. However, there were alternative discursive construc-tions of the meaning of this more rounded picture.

\section{A Rounded Picture: National Comparisons}

The non-executives on the board made it a goal of policy to place WLH on a sound financial footing. A central plank in achieving this objective was by addressing the consultant productivity issue and consultants' particular working practices:

'Two years ago I did not have the data on consultant productivity that we have today. What we now know from having that data is that our consultant body in conventional productivity terms performs less well than their peers throughout the rest of the NHS ... The Executive Medical Director will reply to that that the conventional measure of performance is lacking in various respects in that it doesn't count everything we do, but that of course applies to other Trusts ... But the problem I have with his analysis is that we are in such an extreme position that whatever the benefits are, whatever our low level of counting is, it doesn't account for that substantially lower conventional consultant productivity.' (Interview with the chairman, February 1999)

Indeed, the board minutes from 25 November 1998 document a presen-tation by the director of finance referred to as a 'Report to the Board on Reference Costing'. This presentation makes reference to a 'table' according to which WLH is shown 'to be apparently expensive across a range of procedures and specialties. WLH costs exceeded the national average cost for all but one of the fifteen procedure types presented in the table.' The minutes further document that 'major questions [were raised] over the accuracy of the basic data upon which the analysis rested. This worked to the detriment of WLH and its comparative cost ranking. A genuine comparison was undone by the lack of uniformity in measuring activity.' We could expect medical professionals to throw up such questioning doubts.

Furthermore, the argument was made, in a different setting, that detailed cost comparisons were operational issues that should not preoccupy the board to such an extent. Indeed, exactly where the line between strategy and opera-tional matters should be drawn and exactly where the board's legitimate interest should stop were controversial issues. By implication, what constitutes a broader picture was equally controversial. According to one faction, meeting financial targets was central to the Trust's strategy:

'I think that the role of the non executive director should be to ensure that we are meeting our financial targets and that is a strategic role.' (Interview with the deputy chairman, February 1999)

Indeed, frictions between different perspectives were alluded to (partly retrospectively, partly contemporaneously) in this (second) interview with the non-executive chairman, who contrasted the opportunistic 'pot of gold hunting' of the chief executive with his own, broader vision which encompasses three dimensions, namely, 'quality', 'quantity', and 'amount of resource': 
'I would say that my hankering after financial help and efficiency in conventional terms, that is in conventional input/output terms, is still frustrating immensely to the Chief Executive who regards it as his job to maximise income and that that income is maximised through looking for pots of money in the NHS and his job is to income maximise however opportunistic you have to be to do that. So it's pot of gold hunting. And through pot of gold hunting, you bolster your income, you get through the year, you accomplish all your work, you hit your rates of return by and large, you achieve your change management and you get through and you get by. And efficiency/ effectiveness in the terms that I need them are not seen as the relevant metrics. Getting through is the relevant metric, whereas the relevant metric for me would be quality related to quantity related to the amount of resource that we put into the system. So that friction between two competing understandings is still there.' (Interview with the chairman, February 1999)

It is worth noting that there is a clear rhetorical attempt to claim the (moral) high ground, by contrasting others' opportunism with one's own multi-dimensional perspective. We will see that other factions are pursuing rhetorical strategies that equally claim the high ground in terms of a broader, more strategic perspective.

Somewhat paradoxically, in certain cases, this can involve 'to come down and get more involved in the detail' (Interview with the chairman, February 1999). This also might involve checking whether 'strategic' plans are in place. Indeed, even after the introduction of consultant business cases to support the appointment of new consultants the chair of the audit committee still identified the lack of a staff plan as a main failing within the Trust. He replied as follows to the question 'What would you regard as the main failings then of the Board team?':

'Probably, at the moment, to address the underlying financial issue, not because it is financial but I think it stems from the failure to address the medical staffing issues ... So we don't have a proper staff plan ... I think that is probably the main weakness.' (Interview with NED and chair of the audit committee, February 1999)

In summary, on many occasions the argument was made that the behaviour of the board was a 'problem' in that it was too reluctant to compare the organization's 'performance' more widely with other hospitals. This type of argument was primarily associated with a certain group of people for whom 'performance' was primarily constructed to mean productivity increase and financial balance. There were, however, counter-arguments, which viewed this perspective as too narrow: in fact, these counter-arguments constructed a different type of 'rounded picture'.

\section{A Rounded Picture: The Political Context}

Another approach to constructing a more 'rounded picture' came in the form of reflecting on the broader context in which the organization has to operate, in particular, the political environment. In one episode, this rhetorical strategy was employed in order to engage with attempts to close essential parts of the Trust: 
'Well for the last 15 years politically people have been trying to close the Trust. Three years ago [the District] tried to close the A\&E, which is virtually synonymous with closing the hospital as we know it in its present form. We had to respond to that. We are day-in day-out living with the consequences of responding to a political decision. Which is: 'How do you knock out some hospitals in the Region?' It has a very strong influence on the way we operate day to day.' (Interview with the director of contracting and clinical services and project manager for the Ambulatory Care Unit, November 1996)

The political, regional, and funding contexts thus make up part of the 'rounded picture' that is needed in order to understand WLH's position:

If we take the last two years, I think we have been very successful in retaining the belief, both internally and externally, that we should continue to exist as a broadly based healthcare provider for a particularly needy population. I think that has been very important. I know we can trace it back to the success we had at persuading [the District] to allow us to continue to have an emergency service because after that, all the other discussions were about how you make an emergency service make sense. So I think that was an important starting point, and it set through into generally everyone believing that it is sensible for us to retain services on that site that will broadly speaking be across the board, although I have always believed that there are some things that we did on the site that we should not do, and we will begin to see that unpacking now.' (Interview with the deputy non-executive chairman, February 1999)

Thus, rather than financial balance, it is the continued existence as a 'broadly based ... provider' that is constructed as a necessary political and strategic priority. It is worth pointing out that this political or strategic argument was put forward by somebody who was by no means hostile to arguments of financial discipline. Pursuing a different agenda, the director of nursing and quality, when asked about the failings of the board, criticized an undue focus on 'money':

'Finance takes up about $80 \%$ of any Board meeting and whereas it is important, the primary objectives of the healthcare Trust [are] to deliver health care and in that way, I think the Board has not taken as much interest in what is its core business as it should have done.' (Interview with the director of nursing and quality, February 1999)

In presenting the dominant focus on finance as a distraction from the Trust's 'core business', he is completely in line with the chief executive, who presented trust governance as being about the strategic direction of the organization, rather than being about detailed financial control:

'It's [the board's] weakness that it [ought] to be strategic. [But], particularly in finance it feels that it has to get down to the nitty gritty and it is so difficult to get out of that. That has been the 
problem with the board, ever since the inception of the trust. When you go and see other trust boards, with bigger financial problems than we have got, finance is a cursory item on the agenda. It's the problem of the executive team.' (Interview with the chief executive, November 1996)

Comparisons are also invoked here, but they lead to very different conclu-sions compared to what we discussed in the previous section: the board is too focused on finance and, therefore, not sufficiently strategic. Indeed, from the chief executive's perspective, a complementary return on management effort 
came from exerting 'political' leverage on health authorities, the NHS executive and the treasury. However, he is rhetorically careful not to be seen as against NPM — rather, he wants to be seen as taking a particular perspective on NPM. We can interpret some of his statements such that, in his perspective, cost-saving programmes and efficiency drives are only a narrow aspect of the overall picture. Similarly, the deputy chairman, who also functioned as the chair of the audit committee and who was closely aligned with the theoretical principles of NPM, advocates 'widening out the terms of reference':

'Well my view is that the finances are a way of delivering healthcare, and I think it is much more important to deliver the right healthcare - get the quality right; get the patient through the system and get the right output - and the finances need to match those aims. One of the things I have been trying to do on the Audit Committee is actually widen out the terms of reference ... from just looking at the accounts and figures to looking at both the money, the Audit Commission studies, [and] looking at particular topics in each meeting to try to say "look we're not just talking about pounds here, we're talking about delivery of a service which we need to measure".' (Interview with NED and chair of audit committee, February 1999; emphasis added)

The finance director is accused of narrowness by focusing too much on the financial aspects. However, and this is rhetorically clever, he is praised as having recognized his mistake and being on the road to betterment:

\section{Interviewer:}

[Two years ago] you also said, and this is the final question, 'There is always a tension between the Finance Director and the rest. He wants to control the money, quite rightly, it is his job and everyone else can see ways of spending it. There is a slight tension here but I would not say it is dysfunctional.' Do you still agree with that statement?

\section{Medical Director:}

Yes I would. Was Jon Finance Director? I think he was. It still is his job and he still does it. Actually I think Jon got better at handling that tension and he has noticeably made it his business to understand more about the non-financial side of the business. I think he has developed a lot in the last two years. I think he is now a highly effective finance officer. There still is the tension but it is probably less because he now has matured into someone who (a) has more confidence in his own financial abilities and (b) understands the non-financial aspects of the business better so it is less of a problem than I would have identified two years ago. (Interview with the medical director, February 1999)

The blame for tensions in the past is firmly laid at the door of the 'other faction', but now that they have matured, things are becoming 'less of a problem'. Thus, it is clear that there is a second variation on the theme of adopting a rounded picture: to be less concerned with financial figures, which might be classified as operational matters, and more with the broader political context. The board needs to deal with how best to deliver the whole service, not just one aspect of it. A third 'construction' will be discussed in the section that follows. 


\section{A Rounded Picture: Quality and Innovation}

Implementing the hospital's 'Collaborative Care Teams' (multidisciplinary teams which enable early discharge of patients from the hospital by providing recuperative support for patients in their own home) combined functional efficiency gains from bed reductions with clinical quality enhancements and increased patient satisfaction. Thus, clinical innovation represented a third interpretation of a more 'rounded picture'. The medical director, on some occasions, adopts a similar rhetoric of widening the terms of reference. In response to the question 'What key managerial problems have you faced personally over that period [1997-99]?' the medical director replied:

'Getting quality more up the agenda as opposed to finance. The Board is always totally obsessed with finance.' (Interview with the medical director, February 1999)

So, it is instructive, in this context, to study the negotiation of clinical innovation, the so-called Collaborative Care Team, which looks more widely at patients' care needs, including care provided at their home. As the following quote makes clear, financial pressure is constructed as only a part of the explanation for the innovation.

\section{Interviewer:}

So, in your opinion, why was the Collaborative Team formed?

\section{Medical Director:}

It was formed partly to help us cope with the financial pressure.

Partly because of our philosophy which is of believing that patients should get care in the most appropriate place for that care and that it should be delivered by the most appropriate person ... So it rose out of a belief that here was an opportunity to do it better. Using a number of skills that we have already. (Interview with the medical director, February 1999)

In his role as an executive, he gives a nod to NPM ('financial pressure'), but he then outlines, in his role as a representative of clinical professionals, the care agenda and the employee skilldevelopment agenda. The rhetorical synthesis of finance as stick, and clinical innovation and employee develop-ment as carrot, comes out explicitly in the next statement.

Interviewer:Let me ask the question 'Do you feel that if there had not been cost issues would collaborative care still have been introduced?'

\section{Medical Director:}

If there had not been some financial incentive it probably wouldn't. It is my view that most of these changes happen by a mixture of carrot and stick really. I think in this case it was largely driven by a stick I guess but the carrot was that it was something new that we thought we could make work and it was an extension of stuff we were already doing in the hospital on multiskilling and protocols. Perhaps there was an opportunity to extend our skills into an area where we felt we should be ... I do not think continuous financial pressure is actually the right way to 
keep stimulating innovation ... it is a too vicious mixture. (Interview with the medical director, February 1999) 
With his executive hat on, the medical director acknowledges the positive role of squeeze and pressure; but, later on, with his professional hat on, he cautions against a 'vicious mixture'. The medical director's synthesis claims a broader perspective that prioritizes innovation, and financial discipline as just an element in it. Innovation can help save money, but it needs to be done in a way that takes legitimate professional concerns into account. The director of nursing accomplishes another version of this creative synthesis where clinical issues ('clinical freedom' and 'appropriate care') are acknowledged at the same time as strategic issues ('strategic objectives of the Trust'):

'The idea of the collaborative care team fitted in to the longer term strategy of the Trust which was to re-engineer care and as part of that process to look at a reduction in patient beds. We had already done some research on elective surgical care and knew that there were a range of conditions primarily within orthopaedics, gynaecology, urology where after a day the care required could appropriately be given at home. When you reduce the length of hospital stay you do not necessarily reduce the length of time that care is required. Patients will feel as lousy as they have always felt but it is about identifying and mapping out the clinical process to apportion where appropriate care should be delivered and so the setting up of the team met the strategic objectives of the Trust and at the same time reduced costs by closing almost two wards.' (Interview with the director of nursing and quality, February 1999)

There is reference to clinical issues, care aspects, to how patients feel, to the strategic objectives of the Trust and to cost reduction. The rhetorical project of legitimating professional concerns within, rather than against, the NPM agenda is again pursued in the following statement:

II think if hospitals seriously looked at this [the collaborative care team concept] then the [idea] of hospital beds equalling power and status would go. I think the outrage of patients waiting on trolleys for hours on end in an A\&E Department or overnight in corridors would go. I think that we would be much more efficient. We would be able to use a hospital bed far more appropriately and avoid the mess that is currently the clinical management of health care.' (Interview with the director of nursing and quality, February 1999)

The 'Collaborative Care Team' project, a clinical management innovation, becomes the focus for the simultaneous rhetorical embrace of professional, managerial, and executive objectives: 'patients waiting on trolleys', 'much more efficient', and 'use a ... bed far more appropriately'. Thus, as was argued in the introduction, abstract principles of NPM can find different ways of being interpreted, and professionals will integrate these principles into their existing agendas rather than simply reject them.

However, others will not simply lie down and give up. Indeed, the innova-tion high ground was claimed even by those who were accused of being narrowly finance driven. The finance director, for example, was sometimes highly critical of the professionals' agenda, which was criticized as being very narrowly driven by certain individuals' interest:

'Sometimes I think we end up doing things just because of the sheer weight of doctor pressure which is not necessarily right. I think a good example [is] that there is a debate around step down [a recuperation suite] for ACAD [an ambulatory care and diagnostic centre]. There is an issue around whether or not we put a step down facility 
in ACAD, and you know the arguments did not seem to be around what would provide the best quality of care or in which scenario would the model work best. It seemed to be about whether 2 or 3 individual consultants would buy it or not, and that seems to be dictating the whole direction the Trust was following, which seemed crazy to me.' (Interview with the finance director, February 1999)

Thus, different representatives acknowledge the broader issue of clinical innovation, even if driven by rather different agendas.

\section{Discussion}

The narrative should be seen as a co-construction between us as researchers and authors, the interviewees, and other authors of written documents. Our main objective was to make a plausible account of how different factions appropriate a partly rhetorical project such as 'New Public Management'. A rhetorical strategy is a way of giving expression to an underlying inter-pretive scheme, while taking account of the situational context, as well as opposing views. Rhetorical strategies can be illustrated in conversations and arguments, which were uttered in the presence of an interviewer, but which addressed arguments that were known to have been made in a variety of contexts, including board meetings. Thus, arguments made toward the interviewer were used as approximations for arguments made in a context of board-level interaction.

We distinguished three rhetorical strategies of justifying why a broader picture was necessary. First, there was the argument that the work arrange-ments in this hospital needed to be seen in comparison with other hospitals in the country. Second was the argument that questions of finance needed to be part of a discussion of the broader political context. And, third, there was the argument that finance needed to be seen as part of a broader debate, which was about achieving better care and increased resource efficiency through clinical innovation.

\section{Analysis, Conclusions, and Implications Summary}

We have attempted to analyse board-level interactions, constituted through board-level oral communication, board minutes, letters, and interviews, in order to establish the manner in which principles of NPM actually become invoked in interaction, conversation, and argumentation in the context of what is a pluralistic, professional health organization. We argued that pluralistic organizations manage to function due to the pressure on all factions to engage plausibly with a dominant discourse such as New Public Management. Rather than quarrelling over ideological points, the arguments re.ect each side's attempt to engage constructively with the discourse and to appropriate the discourse for their own agenda(s). It is the role of rhetorical strategies to 
Table 1. Rhetorical Strategies Arguments and a 'Rounded Picture':

\begin{tabular}{|c|c|}
\hline Rhetorical Strategies & Arguments \\
\hline \multirow[t]{5}{*}{$\begin{array}{l}\text { A 'rounded picture' } \\
\text { national comparisons }\end{array}$} & $\begin{array}{l}\text { (1)'our consultant body in conventional productivity terms performs less well than } \\
\text { their peers throughout the rest of the NHS' }\end{array}$ \\
\hline & $\begin{array}{l}\text { (2)'WLH costs exceeded the national average cost for all but one of the fifteen } \\
\text { procedure types' }\end{array}$ \\
\hline & $\begin{array}{l}\text { (3) 'the role of the non-executive director should be to ensure that we are meeting } \\
\text { our financial targets and that is a strategic role' }\end{array}$ \\
\hline & $\begin{array}{l}\text { (4)'[others are opportunistic] the relevant metric for me would be quality related to } \\
\text { quantity related to the amount of resource that we put into the system' }\end{array}$ \\
\hline & $\begin{array}{l}\text { (5)'failure to address the medical staffing issues. ... So we don't have a proper staff } \\
\text { plan' }\end{array}$ \\
\hline \multirow[t]{6}{*}{$\begin{array}{l}\text { A 'rounded picture' } \\
\text { the political context }\end{array}$} & $\begin{array}{l}\text { (1)'We are day-in day-out living with the consequences of responding to a political } \\
\text { decision' }\end{array}$ \\
\hline & $\begin{array}{l}\text { (2)'very successful in retaining the belief, both internally and externally, that we } \\
\text { should continue to exist as a broadly based healthcare provider' }\end{array}$ \\
\hline & (3)'the primary objective of the healthcare trust is to deliver health care' \\
\hline & $\begin{array}{l}\text { (4)'When you go and see other trust boards, with bigger financial problems than we } \\
\text { have got, finance is a cursory item on the agenda' }\end{array}$ \\
\hline & $\begin{array}{l}\text { (5)'it is much more important to deliver the right healthcare ... One of the things I } \\
\text { have been trying to do on the Audit Committee is actually widen out the terms of } \\
\text { reference ... try to say "look we're not just talking about pounds here, we're talking } \\
\text { about delivery of a service"' }\end{array}$ \\
\hline & $\begin{array}{l}\text { (6)'[The] Finance director ... understands the non-.financial aspects of the business } \\
\text { better' }\end{array}$ \\
\hline \multirow{6}{*}{$\begin{array}{l}\text { A 'rounded picture' } \\
\text { improving the clinical } \\
\text { process as a whole }\end{array}$} & (1)'Getting quality more up the agenda as opposed to finance' \\
\hline & $\begin{array}{l}\text { (2)'belief that here was an opportunity to do it better. Using a number of skills that } \\
\text { we have already' }\end{array}$ \\
\hline & $\begin{array}{l}\text { (3)'I do not think continuous financial pressure is actually the right way to keep } \\
\text { stimulating innovation ... it is a too vicious mixture' }\end{array}$ \\
\hline & $\begin{array}{l}\text { (4)'mapping out the clinical process to apportion where appropriate care should be } \\
\text { delivered' }\end{array}$ \\
\hline & $\begin{array}{l}\text { (5)'we would be able to ... avoid the mess that is currently the clinical management } \\
\text { of health care' }\end{array}$ \\
\hline & $\begin{array}{l}\text { (6) 'step down facility in ACAD, and you know the arguments did not seem to } \\
\text { be around what would provide the best quality of care ... It seemed to be about } \\
\text { whether } 2 \text { or } 3 \text { individual consultants would buy it or not' }\end{array}$ \\
\hline
\end{tabular}

accomplish this and to make a convincing case for why change is required. Speci.cally, we identi.ed three rhetorical strategies of justifying why and what kind of broader picture was required: widening the argument to include national productivity comparisons with other hospitals; widening the argu-ment away from a narrow focus on .nance to include the role of the political context; and, lastly, widening the argument to look at innovation in the whole clinical process. 


\section{Engagement with the Literature}

The UK NHS has been described as a 'culture of panics', which means that 'managers and professionals in the NHS find it very difficult to disentangle the urgent from the important' (Pettigrew et al. 1992: 288). Yet the perception of crisis forces a panic or problem up the issue agenda, as happened at ICl (Pettigrew 1985). This potentially beneficial effect of crisis has been termed 'crisis-as-opportunity' (Starbuck et al. 1978), in contrast to 'crisis-as-threat' in a publicsector context (Jick and Murray 1982). One of the key factors distinguishing those NHS sites studied by Pettigrew et al. (1992: 290), which experienced positive change, was what they described as the 'mobilization of crisis' by senior managers. Similarly, Denis et al. (1996) refer to 'financial problems' as a language game that can be instantiated in order to achieve change in a desired direction, specifically the change between two different hospital archetypes. Radical external intervention was referred to as the only means for achieving internal change in a Canadian hospital:

'The Director of Professional Services used persistent financial problems to justify moves that would previously have been rejected ... It became possible in a situation where the Board feared that the Ministry would put the hospital into trusteeship.' (Denis et al. 1996: 681)

Indeed, there has been increasing interest in analysing how (former) public-sector organizations have interpreted, coped with, and responded to the major challenges, in particular financial tightening and ideological managerialism over the past two decades (for example, Greenwood and Lachman 1996). Kitchener et al. (2000: 224), for example, identified substantial 'resilience of traditional patterns' of work structures and processes in local authority social service departments. Generally, there seems to be a mixture of evolution and resilience: Denis et al. (2001) analyse the tensions involved in the change of a governance regime of a hospital organization over the past 20 years or so. We have attempted to contribute to this debate by employing a language perspective, in particular, a focus on the arguments that protagonists use to justify desired changes.

Recent contributions to discourse theory have emphasized the different analytical levels at which discourses can be studied (Alvesson and Karreman 2000) and the need to study discourse not as disembodied texts, but as part of a practice (Hardy et al. 2000). Our perspective acknowledges the need to study language in contexts which incorporate resource dependencies, political realities, business environments, and deeply seated values and beliefs. Hardy et al. (2000: 1244) suggest the concept of 'circuit' in order to analyse when discourses are powerful enough to move from rhetoric to practice and when limits are reached. For example, the alignment of costing and caring and the redefinition of social work have enabled social work professionals to accept some costing work, work that had previously been defined as 'the other' (Llewellyn 1998). Our contribution has been to show how the NPM discourse gets appropriated by different factions, each of whom will put their distinct take on it. We have attempted to show this by focusing on three rhetorical strategies that a 'rounded picture' needed to be adopted. Rather 
than arguing against the managerialists' advocacy of a more rounded picture, others agreed with the rhetoric, but then elaborated on it differentially. As far as a research agenda is concerned, we would argue for the need to study the processes of mutual structuration between language and practice (for example, Hardy et al. 2000; Heracleous and Barrett 2001), and the rhetorical instruments that agents employ in order to make their arguments more effectual.

\section{Note}

Funding from Reed Charity supported the research for this article and the authors would like to acknowledge their thanks for this assistance.

\section{References}

Ackroyd, S., J. Hughes, and K. Soothill

1989 'Public sector services and their management'. Journal of Management Studies 26: 603619.

Alvesson, M., and D. Karreman

2000 'Varieties of discourse: On the study of organizations through discourse analysis'. Human Relations 53/9: 1125-1149.

Anderson-Gough, F., C. Grey, and K. Robson

1998 "'Work hard, play hard": An analysis of organizational cliché in two accountancy practices'.

Organization 5/4: 565-592.

Arnold P. J., and L. S. Oakes

1998 'Accounting as discursive construction: The relationship between Statement of Financial Accounting Standards No. 106 and the dismantling of retiree health bene.ts'. Accounting, Organizations and Society 23/2: 129-153.

Ashburner, L., E. Ferlie, and L. FitzGerald 1996 'Organisational transformation and top-down change: The case of the NHS'. British Journal of Management 7: 1-16.

Bealing, W. E., Jr, M. W. Dirsmith, and T. Fogarty 1996 'Early regulatory actions by the SEC: An institutional theory perspective on the dramaturgy of political exchanges'. Accounting, Organizations and Society 21/4: 317-339.

Borum, F. 1999 'Ascribing rationales to concepts: Opening and closing windows of opportunities at a university hospital'. Paper presented at the 15th EGOS Colloquium, University of Warwick, 4-6 July.

Christensen, T., and P. Laegreid

1999 'New public management - design, resistance, or transformation? A study of how modern reforms are received in a civil service system'. Public Productivity and Management Review 23/2: 169-193.

Coffey, A., and P. Atkinson 
1996 Making sense of qualitative data. London: Sage.

Denis, J.-L., L. Lamothe, and A. Langley

2001 'The dynamics of collective leadership and strategic change in pluralistic organizations'. Academy of Management Journal 44/4: 809-837.

Denis, J.-L., A. Langley, and L. Cazale

1996 'Leadership and strategic change under ambiguity'. Organization Studies 17/4: 673-699.

Eisenhardt, K.

1989 'Building theories from case study research'. Academy of Management Review 14: 532550.

Ferlie, E., L. Ashburner, L. Fitzgerald, and A. Pettigrew

1996 The new public management in action. Oxford: Macmillan.

Greenwood, R., and C. R. Hinings

1993 'Understanding strategic change: The contribution of archetypes'. Academy of

Management Journal

36: 1052-1081.

Greenwood, R., and Lachman, R.

1996 'Change as an underlying theme in professional service organizations: An introduction'. Organization Studies 17/4: 563-572.

Groot, T.

1999 'Budgetary reforms in the non-pro.t sector: A comparative analysis of experiences in health care and higher education in the Netherlands'. Financial Accountability and Management 15/3-4: 353-376.

Hardy, C., I. Palmer, and N. Phillips

2000 'Discourse as a strategic resource'. Human Relations 53/9: 1227-1248.

Harrison, S., and C. J. Pollitt

1994 Controlling health professionals. Buckingham: Open University Press.

Heracleous, L., and M. Barrett

2001 'Organizational change as discourse: Communicative action and deep structures in the context of information technology implementation'. Academy of Management Journal 44/4: 755778.

Hood, C.

1995 'The "new public management" in the 1980s: Variations on a theme'. Accounting, Organizations and Society 20/2-3: 93-109.

Jespersen, P. K.

2000 'The institutionalization and management of quality in the Danish hospital .eld'. Paper presented at the 16th EGOS Colloquium, Helsinki, 2-5 July.

Jick, T. D., and V. V. Murray

1982 'The management of hard times: Budget cutbacks in public sector organizations'.

Organization Studies 3/2: 141-169. 
Kitchener, M.

1998 'Institutional change in U.K. hospitals'. Public Administration 76/1: 73-95.

Kitchener, M.

1999 "'All fur coat and no knickers": Contemporary organisational change in United Kingdom hospitals' in Restructuring the professional organisation: Accounting, health care and law.

D. Brock, M. Powell and C. R. Hinings (eds), 183-199. London: Routledge.

Kitchener, M.

2000 'The "bureaucratization" of professional roles: The case of clinical directors in UK hospitals'. Organization 7/1: 129-154.

Kitchener, M., I. Kirkpatrick, and R. Whipp

2000 'Supervising professional work under new public management: Evidence from an "invisible trade"'. British Journal of Management 11/3: 213-226.

Langley, A.

1999 'Strategies for theorizing from process data'. Academy of Management Review 24/4: $691-710$.

Llewellyn, S.

1998 'Boundary work: Costing and caring in the social services'. Accounting, Organizations and Society 23/1: 23-47.

McNulty, T., and A. Pettigrew

1999 'Strategists on the board'. Organization Studies 20/1: 47-74.

Miles, M. B., and A. M. Huberman

1994 Qualitative data analysis. Newbury Park, CA: Sage.

Pentland, B. T.

1999 'Building process theory with narrative: From description to explanation'. Academy of Management Review 24: 711-724.

Pettigrew, A.

1985 The awakening giant: continuity and change at ICI. Oxford: Blackwell.

Pettigrew, A.

1992 'On studying managerial elites'. Strategic Management Journal 13: 163-182.

Pettigrew, A., E. Ferlie, and L. McKee

1992 Shaping strategic change: Making change in large organizations: The case of the National Health Service. London: Sage.

Richter, I.

1998 'Individual and organisational learning at the executive level'. Management Learning 29/3: 299-316.

Shapiro, B. P.

1998 'Toward a rational model of argumentation for critical accounting discussions'.

Accounting, Organizations and Society 23/7: 641-663.

Silverman, D. 
1993 Interpreting qualitative data: Methods for analyzing talk, text and interaction. London: Sage.

Starbuck, W. H., A. Greve, and B. L. T. Hedberg

1978 'Responding to crisis'. Journal of Business Administration 9: 111-137.

Strauss, A., and J. Corbin

1990 Basics of qualitative research: Grounded theory procedures and techniques. Newbury Park, CA: Sage.

Whittington, R., T. McNulty, and R. Whipp

1994 'Market driven change in professional services - problems and processes'. Journal of Management Studies 31/6: 831-845.

Frank Mueller MA (Konstanz), MSc DPhil (Oxon) holds a Chair in Organization Theory at the University of Leicester. Previously, he had held positions at Royal Holloway University of London, Aston University, and London Business School. His research interests include the following: comparative organizational behaviour and national business systems, the rhetoric and reality of human resource management and team-working, and the 'New Managerialism' in (former) public-sector organi-zations. He has published widely on these topics, including multiple publications in each of the following: Organization Studies, Human Relations, and the Journal of Management Studies. Address: University of Leicester, Management Centre, Leicester LE1 7RH, UK. E-mail: fm26@le.ac.uk

John Sillince is Chair of Knowledge Management at Aston Business School, UK. He conducts research into two areas of organizations. The first is rhetoric, argumentation, identity, and language using discourse analysis. This is both theoretical (attempting to define a distinctively organizational focus for a field that has been in existence for millennia) and empirical (using meetings, interviews, and documents as data). The second is the rhetorical construction of knowledge. Address: Aston Business School, Aston University, Birmingham B4 7ET, UK. Email: j.a.a.sillince@aston.ac.uk

Charles Harvey is Professor of Business History and Management at Bristol Business School, University of the West of England. He holds a PhD in International Business History (Bristol). His research interests are in the fields of strategy, business history, and organization studies. He won the Wadsworth Prize for Business History with his .fist book, The Rio Tinto Company: An Economic History of a Leading International Mining Concern (1981), and again with William Morris: Design and Enterprise in Victorian Britain (1991). He has published widely in journals such as the Journal of Management Studies, Human Relations, and The Economic History Review. He isjoint editor with Professor Geoffrey Jones of the journal Business History. Address: Bristol Business School, University of the West of England, Bristol BS16 1QY, UK.

E-mail: charles.harvey@uwe.ac.uk

Chris Howorth is a Lecturer in Organizational Strategy in the School of Management at Royal Holloway, University of London. His research interests are in the fields of organization studies, health-care management, change management, strategy, and equal opportunities. He has published extensively on health-care reform and management both in the UK and Germany and has carried out work on the education, 
recruitment, and retention of ethnic minorities in a number of industries.

Address: School of Management, Royal Holloway, University of London, Egham, Surrey TW20 0EX, UK.

E-mail: c.howorth@rhul.ac.uk 